Proceedings of the 16th Czech and Slovak Conference on Magnetism, Košice, Slovakia, June 13-17, 2016

\title{
Assessment of the Magnetostrictive Properties of the Selected Construction Steel
}

\author{
A. JUS ${ }^{a, *}, \mathrm{P}$. NOWAK ${ }^{b}$ AND O. GIŃKO ${ }^{a}$ \\ ${ }^{a}$ Institute of Metrology and Biomedical Engineering, Faculty of Mechatronics, Warsaw University of Technology, \\ A. Boboli 8, 02-525 Warsaw, Poland \\ ${ }^{b}$ Industrial Research Institute for Automation and Measurements, Al. Jerozolimskie 202, 02-486 Warsaw, Poland
}

\begin{abstract}
The paper presents results of research on the effects of mechanical stresses on the magnetostrictive properties of 13CrMo4-5 steel. Measurements of stress dependence of magnetostriction fill the gap in the state of the art enabling description of relationships between stresses applied to the samples and its magnetoelastic and magnetostrictive properties. Performed studies represent the starting point for development of unified model of both Villari (magnetoelastic) and Joule (magnetostrictive) effects under stresses in steels. The formulated model will be the basis for the development of generalized methods of interpreting the results of non-destructive testing of the state of the internal stresses in steels based on these phenomena.
\end{abstract}

DOI: 10.12693/APhysPolA.131.1084

PACS/topics: 75.80.+q, 75.50.Bb, 85.70.Ec, 07.55.Ge, 46.25.Hf

\section{Introduction}

Magnetostriction (the Joule effect) is revealed by changes of shape or dimensions of ferromagnetic during its magnetization. These changes can have linear or volume character. Symmetrical effect to magnetostriction is magnetoelastic effect (the Villary effect), which reveals in changes of magnetic properties under external stress [1-3]. These effects are commonly used in application of electromagnetic sensor and actuators $[4,5]$. However nowadays one of main directions of research in this area is a development of non-destructive testing (NDT) method for monitoring of internal and external stresses in ferromagnetic materials.

Current state of art, presented in [6] shows some successes in this matter. On the other hand, universal model of magnetic properties in ferromagnetics (or some group of ferromagnetics - e.g. steels) is required for method commercialization. Such model has to include the relationship between magnetic properties and stresses. In order to explore such relationship, researches are conducted $[2,7]$ and recent advances are presented in the paper. During the tests initial magnetization curve and hysteresis loop with respect to the $B(H)$ and $\lambda(H)$ were simultaneously observed. Thereby full information on the phenomena occurring in the material during magnetization is obtained.

The object of the tests are steel samples (described in Sect. 2). The choice was dictated by major practical significance of the steel as a construction material. In fact, steel is used in almost every branch of industry and there is a great demand for a NDT method enabling determination of the internal stresses and not only existing defects.

*corresponding author; e-mail: ajus@mchtr.pw.edu.pl

\section{Test stand}

Schematic block diagram of the test stand utilized during research is presented in Fig. 1.

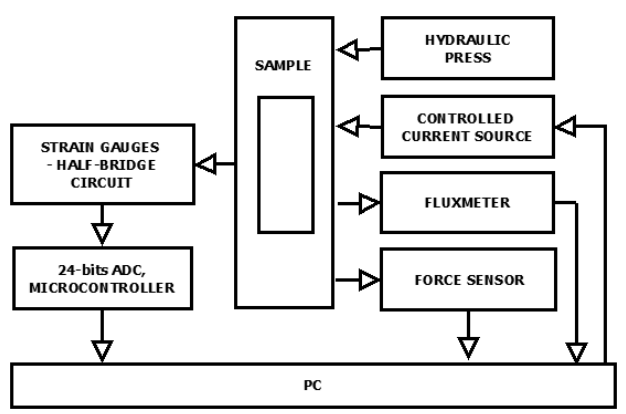

Fig. 1. Schematic block diagram of the test stand [9].

In the center of the test stand in adapted holders (holders are integral parts of the reversor, Fig. 2), a frameshaped sample made of $13 \mathrm{CrMo} 4-5$ steel is placed (samples are known from papers [8-10]). Sample is placed into stresses reversor, which is put into hydraulic press. In this setup, due to the utilization of stresses reversor, compressive stresses are converted into tensile stresses. In order to $\log$ the values of the load reversor is placed on the force sensor, which is connected with $\mathrm{PC}$ via data acquisition card.

The tested sample has magnetizing and measuring windings. The samples' magnetizing windings are powered from software controlled power supply, while their measuring windings are connected with fluxmeter. Samples are equipped with strain gauges to measure their deformation (magnetostriction). Such strain gauges operate in a Wheatstone half-bridge configuration [11]. Two active strain gauges are adhered to the stressed sample, while other two strain gauges are placed on a reference sample with a specially prepared self-compensate mag- 
netizing winding. Reference sample is not stressed so it is placed freely (not in reversor) in the vicinity of the tested sample. Such configuration provides a compensation of environmental conditions changes (especially temperature variation).

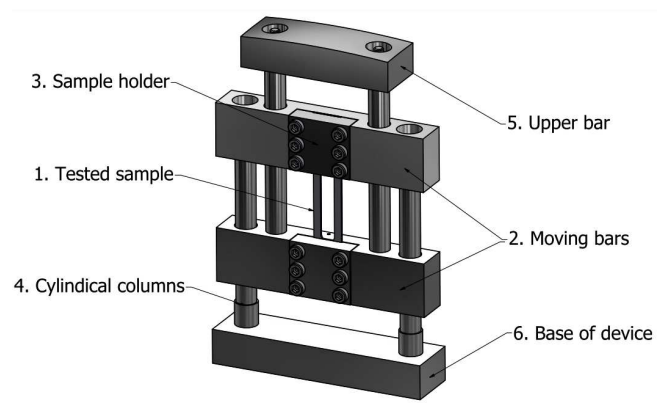

Fig. 2. Stresses reversor - device for the conversion of the compressive stresses into the tensile stresses [9].

Tested and reference samples have been wounded in the same way (each column have 300 magnetizing and 100 measuring windings). Both samples (tested and reference) differ in the way of column magnetizing windings connection. For tested sample windings are connected in a way which strengthens the magnetizing field while reference sample magnetizing windings are connected in a way which reduces the magnetic field to zero. The same current flows through samples magnetizing windings (which ensures similar way of the heat up and thermal expansion), but only the tested sample is exposed to the changes in magnetic field.

Samples are made of interesting material — structural steel dedicated for work in high temperatures up to about $550^{\circ} \mathrm{C}$. Magnetoelastic properties of this material have already been presented in [8, 10]. Samples parameters are summarized in Table I.

TABLE I

Summary of the samples parameters.

\begin{tabular}{l|c}
\hline \hline Parameter & Value \\
\hline cross-sectional dimensions of & $8 \mathrm{~mm} \times 2 \mathrm{~mm}$ \\
columns & \\
yield strength $R_{e}$ & $280 \mathrm{MPa}$ \\
tensile strength $R_{m}$ & $450-600 \mathrm{MPa}$ \\
max. temperature of work & $550^{\circ} \mathrm{C}$ \\
material & $13 \mathrm{CrMo} 4-5$ \\
magnetizing windings & $600(300$ per column $)$ \\
measuring windings & $200(100$ per column $)$
\end{tabular}

More detailed description of the construction and operation of the test stand has been presented in the paper [9].

\section{Results}

Samples were magnetized by the field of parameters: — triangular supply current,
-0.25 period,

- magnetic field range: $[0 \div 3 \mathrm{kA} / \mathrm{m}]$

- frequency $0.05 \mathrm{~Hz}$.

Before and after the measurement the samples were degaussed with the usage of sinusoidal fading signal. The measurements were performed at different tensile loadings in the range of $0-8 \mathrm{kN}$ (with $1 \mathrm{kN}$ increment) with corresponding stresses 0-250 MPa with $31.25 \mathrm{MPa}$ increment.

The results are used for evaluation of the stress state in the material. In Fig. 3 characteristics of samples' dimensions variation (magnetostriction) in the function of magnetic field for primary magnetization curve are presented. Characteristics are shown only to the point of dimensions stabilization (or to the point of magnetostriction change from positive to negative). At higher loads stabilization of the dimensions variation is obtained at lower field values, so presented characteristics terminate at different points. These characteristics are particularly easy to obtain - only part of single magnetization cycle allows to get information about stresses in the material. In order to obtain such characteristics there is no need for measurement of magnetic induction.

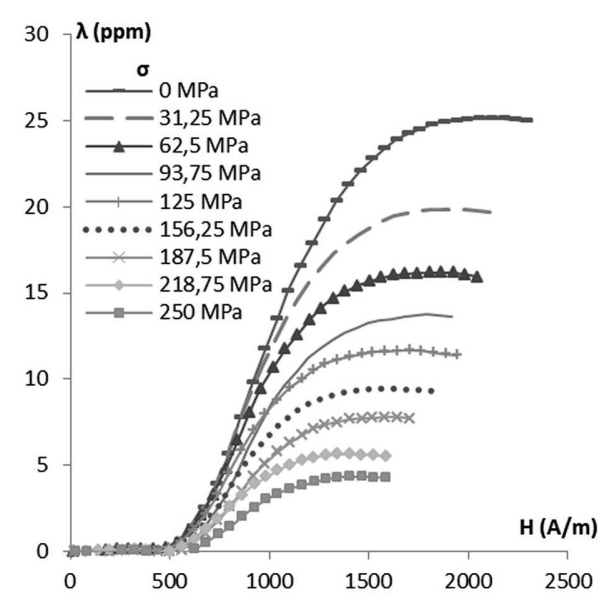

Fig. 3. Summary of the characteristics of magnetostriction in function of magnetic field for differ stresses (0-250 MPa).

Presented family of characteristics includes several important information, which can be easily used to determine the state of the stress in the material:

- magnetostriction of the stabilization point - maximum value of the magnetostriction in characteristics presented in Fig. 3,

- inclination angle of the magnetostriction curves.

The advantage of the second information is that there is no need to obtain characteristics stabilization - thus lower magnetic field is sufficient to its determination. On the other hand, the values of magnetostriction stabilization point are easier to interpret - but only if the value of magnetizing field is high enough. Presented results of the tests contain this data, so characteristic of the mag- 


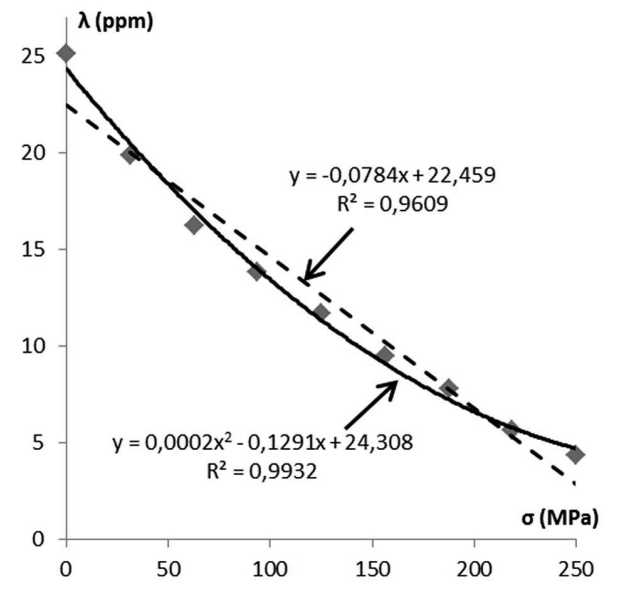

Fig. 4. Characteristic of the magnetostriction stabilization point in the function of tensile stresses.

netostriction value in stabilization point in function of tensile stresses was determined and is presented in Fig. 4.

For obtained data points, 1st and 2nd degree polynomials were fitted, using the least squares method. Next to the fitted curves, coefficient of determination $R^{2}$ was calculated. For 1st degree curve obtained coefficient of determination of 0.9609 , while for 2 nd degree curve $0.9932[12]$.

\section{Conclusions}

Presented studies are pointing the possibility of utilization of the magnetostriction measurements in steel samples to evaluate their state of the stresses. In the study magnetostriction in the initial magnetization of the sample at its differ loadings was measured. The maximum values of these deformations are correlated with the applied loads. Fitted to characteristic in Fig. 4 trend lines correspond very well with the experimental results [12]. Especially 2nd degree polynomial has very high correlation coefficient.

To obtain the presented results there is no necessity to measure the magnetic flux in the sample, which reduces the number of devices involved in the measurements. However, in this case the results are confined only to the samples of specific dimensions. Therefore, more universal would be model, in which the magnetizing field will be replaced by the magnetization of the sample material. However it requires carrying out a measurements of induction in the sample. Another solution is to develop a model that allows a generalization of the results - where only magnetizing field and objects dimension will be enough to determine state of the stresses in the material. Further research will be conducted in those ways.
Another benefit of this ongoing work is to obtain more data about magnetic parameters of the steel, despite the magnetoelastic properties [8, 10]. It will allow further development of a general model of magnetic phenomena in materials $[13,14]$.

\section{Acknowledgments}

This work was partially supported by the statutory founds of Institute of Metrology and Biomedical Engineering, Warsaw University of Technology (Poland).

\section{References}

[1] A. Szewczyk, A. Wiśniewski, R. Puźniak, H. Szymczak, Magnetyzm i nadprzewodnictwo, PWN, Warszawa 2012.

[2] D.C. Jiles, Introduction to Magnetism and Magnetic Materials, Chapman and Hall, London 1998.

[3] A.H. Morrish, The Physical Principles of Magnetism, Wiley-VCH, 2001.

[4] F. Claeyssen, N. Lhermet, R. Le Letty, P. Bouchilloux, J. Alloys Comp. 258, 61 (1997).

[5] J. Salach, A. Bienkowski, R. Szewczyk, J. Magn. Magn. Mater. 316, 607 (2007).

[6] P. Vourna, A. Ktena, A. Mpalliou, A.G. Mamalis, E. Hristoforou, Mater. Sci. Forum 792, 139 (2014).

[7] A. Ktenaand, E. Hristoforou, IEEE Trans. Magn. 48, 1433 (2012).

[8] D. Jackiewicz, R. Szewczyk, J. Salach, A. Bieńkowski, M. Kachniarz, in: Recent Advances in Automation, Robotics and Measuring Techniques. Advances in Intelligent Systems and Computing, Vol. 267, Eds. R. Szewczyk, C. Zieliński, M. Kaliczyńska, Springer, Cham 2014, p. 607.

[9] O. Gińko, A. Juś, R. Szewczyk, in: Challenges in Automation, Robotics and Measurement Techniques. Advances in Intelligent Systems and Computing, Vol. 440, Eds. R. Szewczyk, C. Zieliński, M. Kaliczyńska, Springer, Cham 2016, p. 843.

[10] M. Kachniarz, D. Jackiewicz, M. Nowicki, A. Bieńkowski, R. Szewczyk, W. Winiarski, in: Mechatronics - Ideas for Industrial Application. Advances in Intelligent Systems and Computing, Vol. 317, Eds. J. Awrejcewicz, R. Szewczyk, M. Trojnacki, M. Kaliczyńska, Springer, Cham 2015, p. 607.

[11] Z. Rolinski, Resistance Tensometry, WNT, Warszawa 1981 (in Polish).

[12] A.A. Aczel, Statistics in Administration, PWN, 2011 (in Polish).

[13] R. Szewczyk, A. Bienkowski, J. Salach, J. Magn. Magn. Mater. 320, 1049 (2008).

[14] D. Jackiewicz, R. Szewczyk, J. Salach, A. Bieńkowski, Acta Phys. Pol. A 126, 392 (2014). 